\title{
KARAKTERISASI PLASTIK BIODEGRADABEL DARI LDPE-g-MA DAN PATI TANDAN KOSONG SAWIT
}

\author{
Selfa Dewati Samah ${ }^{1}$, Tengku Rachmi Hidayani ${ }^{2}$, Elda Pelita ${ }^{3}$ dan Gusfiyesi ${ }^{4}$ \\ ${ }^{1-4}$ Jurusan Analis Kimia, Politeknik ATI Padang, Padang, Sumatera Barat \\ gusfiyesi@yahoo.com, selfasamah05@gmail.com,rachmihidayani@yahoo.com, \\ elda726@gmail.com
}

\begin{abstract}
Penelitian ini bertujuan untuk menghasilkan suatu plastik biodegradabel yang dapat terurai di alam, sehingga dapat menjadi salah satu solusi dalam penumpukan sampah plastik yang sulit diuraikan oleh alam. Plastik biodegradabel yang dihasilkan dari pencampuran limbah plastik polietilena jenis Low Density Polyetylene (LDPE) dengan pati Tandan kosong Sawit (TKS) yang dimodifikasi dengan menambahkan maleat anhidrida sebagai agen pengikat silang. Untuk menghasilkan plastik biodegradabel dilakukan variasi perbandingan tertentu antara limbah LDPE, pati TKS, maleat anhidrida dan benzoil peroksida (90:10:1:1), (80:20:1:1), (70:30:1:1), (60:40:1:1). Tahapan penelitian ini melakukan ekstraksi pati dari tandan kosong sawit (TKS), preparasi serbuk plastik biodegradabel dengan metode refluks menggunakan pelarut xilena dari berbagai variasi komposisi limbah LDPE, pati TKS, maleat anhidrida, dan benzoil peroksida, pencetakkan plastik biodegradabel dengan metode kempa tekan dan karakterisasi terhadap hasil plastik biodegradabel yaitu analisa sifat mekanik dengan uji kuat tarik dan kemuluran, analisa kemampuannya terurai di alam dengan uji biodegradabel, dan analisa sifat kimianya dengan uji FTIR. Dari hasil karakterisasi dapat diperoleh kondisi optimum plastik biodegradabel yang dihasilkan Plastik biodegradabel dengan perbandingan Limbah LDPE, Pati TKS, maleat anhidrida, benzoil peroksida (60:40:1:1) yang memiliki kemampuan terurai pada tanah sampah yaitu sebesar 9,032\%, harga kuat tarik $6,9410 \mathrm{~N} / \mathrm{m}^{2}$ dan nilai kemuluran $3,1875 \%$, analisa sifat kimia dengan uji FT-IR menunjukan bilangan gelombang yang khas untuk ikatan antara limbah LDPE-g-MA dan Pati TKS yaitu $1165,00 \mathrm{~cm}^{-1}$ yang menunjukan gugus fungsi $\mathrm{C}-\mathrm{O}$ bending .
\end{abstract}

Keywords: plastik biodegradabel, limbah LDPE, Pati, Tanda Kosong Sawit

\section{PENDAHULUAN}

Kemasan plastik merupakan bahan yang banyak dimanfaatkan oleh produsen maupun masyarakat. Bahkan setiap membeli satu produk di pasar tradisional maupun swalayan selalu diberikan kemasan plastik untuk membungkusnya. Pemerintah sudah mulai memikirkan bagaimana menekan jumlah penggunaan plastik di Indonesia. Salah satu usaha pemerintah yaitu dengan mengharuskan konsumen membayar setiap tas plastik yang digunakan dengan harga yang cukup tinggi, namun hal ini belum akan cukup untuk mengatasi limbah plastik yang ada di lingkungan. Senyawa plastik merupakan senyawa yang sukar terdegradasi secara alami sehingga akan menyebabkan penumpukan limbah plastik diberbagai tempat.

Alternatif yang tepat yaitu membuat kemasan plastik yang dapat terdegradasi dengan cara mengkombinasikannya dengan bahan hayati. Salah satu jenis 
plastik yang digunakan sebagai kemasan kantong plastik adalah jenis polietilena. Telah dilakukan berbagai penelitian untuk menghasilkan plastik biodegradabel, diantaranya dengan menambahkan pati yang bersumber dari biji durian dan limbah plastik polipropilena dengan bantuan maleat anhidrida sebagai agen pengikat silang dan benzoil peroksida sebagai inisiator. Diperoleh kondisi optimum plastik biodegradabel yang dihasilkan adalah pada perbandingan limbah PP, pati biji durian, maleat anhidrida dan benzoil peroksida (94:6:1:1). Plastik biodegradabel yang dihasilkan memiliki ikatan kimia, sifat mekanik dan kemampuan terurai dialam yang baik. Namun, pada analisa morfologi, didapatkan pencampuran yang kurang homogen antara pati dengan polipropilena karena rentang perbedaan titik lebur yang besar (Pelita, 2015) Untuk mengatasi perbedaan rentang titik lebur tersebut, perlu dicarikan bahan plastik yang memiliki titik lebur yang mendekati pati yaitu polietilen. Penelitian pembuatan plastik biodegradabel dari polietilen telah dilakukan oleh Sudhakar (2010) yang mengamati proses degradasi berbagai jenis polietilen, dan mendapatkan hasil polietilen jenis LDPE (Low Density Polyethylene) dengan penambahan pati memiliki sifat biodegradasi yang paling baik. Penelitian mengenai plastik biodegradabel dengan bahan dasar LDPE dan pati komersil yang ada dipasaran dengan bantuan benzoil peroksida dan tanpa benzoil peroksida sebagai inisiator telah dilakukan oleh Kaur (2010) dengan hasil penurunan massa maksimum pada uji biodegradabel didapatkan pada polietilena yang digrafting dengan pati dengan bantuan benzoil peroksida.
Penelitian mengenai pencampuran LDPE dengan pati ubi dengan penambahan asam akrikat telah dilakukan oleh Susilawati (2011) dimana kondisi optimum didapatkan pada perbandingan LDPE dan pati 6:4 dengan kekuatan tarik $0,38 \mathrm{Kgf} / \mathrm{mm}^{2}$, namun memiliki ikatan kimia yang lemah. Ikatan kimia yang lemah dari plastik biodegradabel ini disebabkan karena perbedaan sifat antara pati dan plastik LDPE. Untuk mengatasi perbedaan sifat antara pati dan LDPE, perlu ditambahkan suatu bahan agen pengikat silang antara pati dan plastik LDPE.

Penelitian mengenai penggunaan maleat anhidrida sebagai agen pengikat silang telah dilakukan oleh Ghaemy (2012) yang berusaha menggrafting PE yang menghasilkan ikatan kimia yang baik antara plastik dengan pati. Pati biji durian yang telah digunakan pada penelitian sebelumnya memiliki hasil yang baik dalam pencampurannya dengan limbah polipropilena. Namun, durian merupakan buah musiman yang dikhawatirkan ketersediaannya setiap saat akan terbatas pada waktu tertentu. Sehingga diperlukan sumber pati lain yang ketersediaannya dalam jangka panjang dan sumbernya mudah didapatkan. Tandan kosong sawit merupakan limbah yang tidak memiliki nilai jual selama ini (Rutkowska, 2002).

Pemanfaatan tandan kosong sawit telah dilakukan oleh Junaidi (2015) yang memanfaatkan serat dari tandan kosong sawit menjadi papan komposit. Berdasarkan uraian tersebut, peneliti ingin melakukan suatu penelitian pembuatan plastik biodegradabel dengan limbah plastik polietilena (PE) jenis LDPE (low density polyethylene) dan pati tandan kosong sawit (TKS) dengan penambahan maleat anhidrida sebagai 
agen pengikat silang, benzoil peroksida sebagai inisiator. Ekstraksi pati dari TKS dengan menggunakan metode perendaman dengan air, proses pencampuran pembentukan plastik biodegradabel dengan metode refluks dengan menggunakan pelarut xilena, serta proses pencetakan plastik biodegradabel dengan metode cetak tekan (hot press). Karakterisasi dari plastik biodegradabel yang dihasilkan dilakukan dengan analisa sifat mekanik dengan uji tarik, analisa gugus fungsi dengan FTIR, analisa sifat termal dengan uji DTA, analisa sifat morfologi dengan Uji SEM dan analisa kemampuan terurai dengan uji biodegradabel.

\section{BAHAN DAN METODE PENELITIAN \\ Bahan dan alat penelitian}

Bahan yang digunakan dalam penelitian ini adalah: Limbah LDPE dari limbah kantong plastik buah, pelarut xilena, metanol, aseton, benzoil peroksida, maleat anhidrida, tandan kosong sawit, air.

Peralatan yang digunakan dalam penelitian ini adalah : Neraca Analitis dengan merk Mettler Toledo (range 4 desimal, maksimal 500 gram) , Labu refluks ukuran $500 \mathrm{~mL}$ merk Pyrex, Magnetik Stirer, Alat Pemanas Stirer merk PMC, Pendingin Liebig merk Pyrex, Oven listrik merk Memmert, Alat Cetak Tekan merk Torsee SC-2DE, Alatalat gelas merk Pyrex, Seperangkat alat uji tarik Type SC-2DE CAP 2000 kgf kapasitas $1 \mathrm{~kg}$ dengan range suhu 80$350^{\circ} \mathrm{C}$, Termometer raksa $10-400^{\circ} \mathrm{C}$, Blender merk National, Ayakan 140 mesh merk Tantalum 3N8 Purity, dan seperangkat alat Fourier Transform
Infrared Spectroscopy (FT-IR) Shimadzu IRAffinity-1S.

\section{Metode Penelitian}

Penelitian ini bersifat eksperimental laboratorium yang dilakukan dalam beberapa tahapan:

Pertama, dilakukan pengambilan pati biji durian dangan cara tandan kosong sawit dibelah dipisahkan dari kulit kerasnya. Serbuk TKS dibersihkan dari pengotor dan dicuci dengan air. Serbuk TKS direndam sambil diaduk selama 1 jam kemudian disaring. Ampas dibuang, air pati diendapkan kembali lalu disaring sehingga didapatkan pati basah. Pati TKS dipanaskan pada suhu $50^{\circ} \mathrm{C}$ selama 6 jam. Kemudian diayak 140 mesh sehingga didapatkan pati TKS yang halus dan kering Tahapan kedua adalah Pembuatan Serbuk Plastik Biodegradabel dimana limbah polietilena jenis LDPE yang bersumber dari limbah kemasan plastik pengemas buah di supermarket dibersihkan dan dipotong kecil dengan ukuran $0.5 \quad \mathrm{x} \quad 0,5 \mathrm{~cm}$. Dimasukkan kedalam labu alas dan direfluks dengan pelarut xilena pada suhu $110^{\circ} \mathrm{C}$ selama 2 jam. Ditambahkan maleat anhidrida dan benzoil peroksida sesuai perbandingan dan direfluks kembali selama 30 menit, terakhir ditambahkan pati TKS sesuai perbandingan dan direfluks kembali selama 30 menit. Diendapkan larutan plastik biodegradabel dengan menggunakan metanol. Dikeluarkan dan dikeringkan serta dihaluskan sehingga menjadi serbuk plastik biodegradabel, diayak dengan ayakan 140 mesh. 


\section{Eksakta Vol. 18 No. 2 Oktober $\mid 2017$}

E-ISSN : 2549-7464, P-ISSN : 1411-3724

Tabel.1 Perbandingan Komposisi serbuk limbah polietilena, pati TKS, maleat anhidrida dan benzoil peroksida

\begin{tabular}{ccccc}
\hline No & $\begin{array}{c}\text { Serbuk Limbah } \\
\text { LDPE }(\%)\end{array}$ & $\begin{array}{c}\text { Pati TKS } \\
(\%)\end{array}$ & $\begin{array}{c}\text { Maleat Anhidrida } \\
(\text { MA) }(\%)\end{array}$ & $\begin{array}{c}\text { Benzoil Peroksida } \\
(\text { BPO })(\%)\end{array}$ \\
\hline 1 & 100 & 0 & 0 & 0 \\
\hline 2 & 90 & 10 & 1 & 1 \\
\hline 3 & 80 & 20 & 1 & 1 \\
\hline 4 & 70 & 30 & 1 & 1 \\
\hline 5 & 60 & 40 & 1 & 1 \\
\hline 6 & 50 & 50 & & 1
\end{tabular}

Tahap ketiga adalah proses cetak tekan plastik biodegradable, yaitu dengan cara serbuk Plastik biodegradabel dengan berbagai variasi dan komposisi massa yang telah dihasilkan dimasukkan kedalam alat cetak tekan dan ditekan pada alat tekan hidrolik dengan tekanan 150 $\mathrm{kg} / \mathrm{cm}^{2}$ pada temperatur $110^{\circ} \mathrm{C}$ selama 15 menit. Hasil yang diperoleh didinginkan pada suhu kamar dan dikeluarkan dari dalam cetakan. Tahap akhir adalah karakterisasi plastik biodegradabel yang dihasilkan dengan Analisa sifat mekaniknya dengan uji Tarik, analisa gugus fungsinya dengan uji FTIR, dan analisa kemampuannya terurai dialam dengan uji biodegradabel.

HASIL DAN PEMBAHASAN Analisa Sifat Mekanik dengan Uji Kekuatan Tarik dan Kemuluran

Dari hasil penelitian ini didapatkan data analisa kekuatan tarik dan kemuluran dari plastik biodegradabel dari pati biji durian dan limbah plastik polipropilena dengan penambahan benzoil peroksida dan maleat anhidrida berbagai variasi komposisi massa adalah sebagai berikut :

Tabel 2. Hasil Perhitungan Uji Mekanik Plastik Biodegradabel

\begin{tabular}{|c|c|c|c|c|}
\hline No & $\begin{array}{c}\text { Perbandingan (komposisi } \\
\text { dan massa) }\end{array}$ & $\begin{array}{l}\text { Yield } \\
\text { Strength } \\
\left(\mathrm{N} / \mathrm{m}^{2}\right)\end{array}$ & $\begin{array}{l}\text { Kuat Tarik } \\
\qquad\left(\mathrm{N} / \mathrm{m}^{2}\right)\end{array}$ & $\begin{array}{c}\text { Kemul } \\
\text { uran } \\
(\%)\end{array}$ \\
\hline 1 & Limbah LDPE & 56,848 & 17,878 & 10,2969 \\
\hline 2 & $\begin{array}{l}\text { Limbah LDPE, Pati TKS, maleat } \\
\text { anhidrida, benzoil peroksida }\end{array}$ & 55,922 & 17,586 & 9,876 \\
\hline 3 & $(90: 10: 1: 1)$ & 50,913 & 16,010 & 9,25 \\
\hline 4 & $\begin{array}{l}\text { Limbah LDPE, Pati TKS, maleat } \\
\text { anhidrida, benzoil peroksida } \\
(80: 20: 1: 1)\end{array}$ & 32,765 & 10,3035 & 7,625 \\
\hline 5 & $\begin{array}{l}\text { Limbah LDPE, Pati TKS, maleat } \\
\text { anhidrida, benzoil peroksida } \\
\text { (70:30:1:1) } \\
\text { Limbah LDPE, Pati TKS, }\end{array}$ & 22,072 & 6,9410 & 3,1875 \\
\hline
\end{tabular}




\section{Eksakta Vol. 18 No. 2 Oktober 2017}

E-ISSN : 2549-7464, P-ISSN : 1411-3724

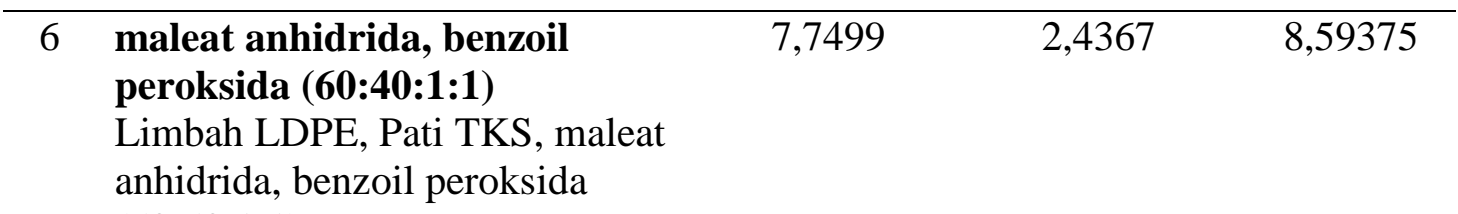

(50:50:1:1)

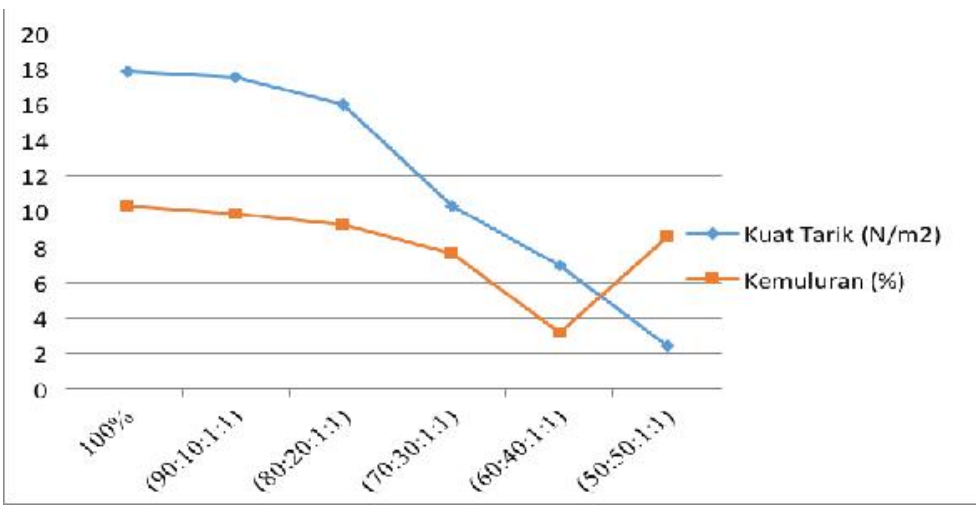

Gambar 1.Grafik Kuat Tarik $\left(\mathrm{N} / \mathrm{m}^{2}\right)$ dan Kemuluran (\%) dari Plastik Biodegradabel yang dihasilkan

Sifat plastik biodegradabel yang diharapkan adalah memiliki kuat tarik yang baik dan nilai kemuluran di bawah $5 \%$ yang menunjukkan berkurangnya sifat polimer sintetis dari plastik tersebut. Dari tabel 5 dapat dilihat bahwa karakteristik mekanik komposit plastik biodegradabel yang dihasilkan yang paling memenuhi harapan sesuai dengan nilai standard tentang plastik biodegradabel adalah plastik biodegradabel dengan perbandingan Limbah LDPE, Pati TKS, maleat anhidrida, benzoil peroksida $(60: 40: 1: 1)$ dengan harga kuat tarik $6,9410 \mathrm{~N} / \mathrm{m}^{2}$ dan nilai kemuluran 3,1875\%.

\section{HASIL DAN PEMBAHASAN} Analisa Kemampuannya Terurai di Alam dengan Uji Biodegradasi

Penguburan spesimen yang dilakukan pada 3 jenis tanah yaitu tanah sampah, tanah biasa, dan pasir bertujuan untuk melihat tingkat biodegradasinya di alam. Tingkat biodegradasi dalam tanah ini diamati dengan nilai penurunan berat plastik biodegradabel setelah penguburan selama 30 hari dengan pengamatan setiap 10 hari. Uji biodegradasi pada penguburan dalam tanah memperlihatkan degradasi yang nyata selama 30 hari untuk semua spesimen secara gravimetri (Siswanto, 2007). Pada tabel 3 dapat dilihat besarnya penurunan berat plastik biodegradabel sejalan dengan penambahan pati pada pembuatan plastik biodegradabel kecuali pada perbandingan Limbah LDPE, Pati TKS, maleat anhidrida, benzoil peroksida (50:50:1:1) yang mungkin disebabkan oleh karena jumlah antara polimer sintetis dan polimer alam yang sama banyak mengakibatkan hilangnya sifat polimer sintetis sehingga ikatan kimia yang terbentuk kuat dan sulit diuraikan oleh bakteri. Harga penurunan berat yang paling besar pada plastik biodegradabel dengan perbandingan Limbah LDPE, 


\section{Eksakta Vol. 18 No. 2 Oktober 2017}

E-ISSN : 2549-7464, P-ISSN : 1411-3724

Pati TKS, maleat anhidrida, benzoil peroksida (60:40:1:1)di tanah sampah yaitu 9,032\%. Faktor penyebab penurunan berat maksimum di tanah sampah diduga karena tanah sampah memiliki lebih banyak nutrisi dan adanya Tabel 3. Data Hasil Penurunan Massa (\%) Spesimen Plastik biodegradabel Setelah Penanaman dalam Tanah

\begin{tabular}{|c|c|c|c|c|c|c|}
\hline \multirow{2}{*}{$\begin{array}{l}\text { Variasi Komposisi } \\
\text { Spesimen (\%) }\end{array}$} & \multirow[t]{2}{*}{ Jenis Tanah } & \multicolumn{4}{|c|}{$\begin{array}{l}\text { Penurunan Massa Spesimen Setelah Penanaman } \\
\text { (gram) }\end{array}$} & \multirow{2}{*}{$\begin{array}{l}\text { Penurun } \\
\text { an Massa } \\
\text { (\%) }\end{array}$} \\
\hline & & Awal & 10 Hari & 20 Hari & 30 Hari & \\
\hline \multirow{3}{*}{$\operatorname{LLDPE}(100)$} & 1. Pasir & 1. 0,3754 & 1. 0,3754 & 1. 0,3752 & 1. 0,3751 & 1. 0,080 \\
\hline & 2. Tanah Biasa & 2. 0,3339 & 2. 0,3339 & 2. 0,3337 & 2. 0,3337 & 2. 0,539 \\
\hline & 3. Tanah Sampah & 3. 0,2161 & 3. 0,2161 & 3. 0,2158 & 3. 0,2158 & 3. 0,138 \\
\hline \multirow{3}{*}{$\begin{array}{l}\text { LLDPE : PTKS : MA : BPO } \\
(90: 10: 1: 1)\end{array}$} & 1. Pasir & 1. 0,2710 & 1. 0,2672 & 1. 0,2667 & 1. 0,2660 & $1.1,84$ \\
\hline & 2. Tanah Biasa & 2. 0,2377 & 2. 0,2346 & 2. 0,2339 & 2. 0,2339 & 5 \\
\hline & 3. Tanah Sampah & 3. 0,2678 & $3.0,2641$ & 3. 0,2631 & 3. 0,2611 & $\begin{array}{l}2.1,598 \\
3.2,501\end{array}$ \\
\hline \multirow{3}{*}{$\begin{array}{l}\text { LLDPE : PTKS : MA : BPO } \\
(80: 20: 1: 1)\end{array}$} & & & & & & $1.2,21$ \\
\hline & 2. Tanah Biasa & 2. 0,2589 & $\begin{array}{l}1.0,3153 \\
2.0,2557\end{array}$ & 2. 0,2539 & $\begin{array}{l}1.0,3084 \\
2.0,2535\end{array}$ & 9 \\
\hline & 3. Tanah Sampah & 3. 0,2926 & 3. 0,2890 & 3. 0,2875 & 3. 0,2869 & $\begin{array}{l}2.2,085 \\
3.1,94\end{array}$ \\
\hline \multirow{4}{*}{$\begin{array}{c}\text { LLDPE : PTKS : MA : BPO } \\
(70: 30: 1: 1)\end{array}$} & 1. Pasir & & & & & $1.2,37$ \\
\hline & 2. Tanah Biasa & $\begin{array}{l}\text { 1. } 0,43 / 5 \\
2.03935\end{array}$ & $\begin{array}{l}1.0,4302 \\
203561\end{array}$ & $\begin{array}{l}\text { 1. } 0,4252 \\
0.3840\end{array}$ & $\begin{array}{l}\text { 1. } 0,42 / 1 \\
2.03832\end{array}$ & 7 \\
\hline & 3. Tanah & $\begin{array}{l}\text { 2. } 0,3935 \\
3.04047\end{array}$ & $\begin{array}{l}2.0,5561 \\
303979\end{array}$ & $\begin{array}{l}\text { 2. } 0,3840 \\
3.03956\end{array}$ & $\begin{array}{l}2.0,3832 \\
3.03030\end{array}$ & $2.2,617$ \\
\hline & Sampah & & & & $3.0,3939$ & $3.2,668$ \\
\hline \multirow{3}{*}{$\begin{array}{l}\text { LLDPE : PTKS : MA : BPO } \\
(60: 40: 1: 1)\end{array}$} & 1. Pasir & 1. 0,2172 & 1. 0,2132 & 1. 0,2115 & 1. 0,210 & $1.3,31$ \\
\hline & 2. Tanah Biasa & 2. 0,2053 & 2. 0,2010 & 2. 0,1986 & 2. 0,1950 & 4 \\
\hline & $\begin{array}{l}\text { 3. Tanah } \\
\text { Sampah }\end{array}$ & 3. 0,1860 & 3. 0,1823 & 3. 0,1807 & 3. 0,1792 & $\begin{array}{l}2.5,017 \\
\mathbf{3 . 9 , 0 3 2}\end{array}$ \\
\hline \multirow{3}{*}{$\begin{array}{l}\text { LLDPE : PTKS : MA : BPO } \\
(50: 50: 1: 1)\end{array}$} & & & & & & $1.4,06$ \\
\hline & $\begin{array}{l}\text { 1. Pasir } \\
\text { 2. Tanah Biasa }\end{array}$ & $\begin{array}{l}1.0,3 / 3 / \\
2.0 .3814\end{array}$ & $\begin{array}{l}1.0,3650 \\
2.0,3724\end{array}$ & $\begin{array}{l}\text { 1. } 0,3602 \\
2.03674\end{array}$ & $\begin{array}{l}1.0,3585 \\
203661\end{array}$ & 7 \\
\hline & $\begin{array}{l}\text { 2. I anan Blasa } \\
\text { 3. Tanah Sampah }\end{array}$ & 3. 0,3055 & 3. 0,2952 & $\begin{array}{l}\text { 2. } 0,36 / 4 \\
\text { 3. } 0,2945\end{array}$ & $\begin{array}{l}2.0,0001 \\
\text { 3. } 0,2928\end{array}$ & $2.4,01$ \\
\hline
\end{tabular}

Penguburan spesiman dilakukan pada beberapa jenis tanah selama 30 hari dengan pengamatan setiap 10 hari. Berdasarkan tabel di atas memperlihatkan laju pengurangan massa yang tidak begitu besar. Suatu penelitian yang telah dilakukan oleh Forensic Science Researches Northrop and Rowe (1987) dalam jurnal Springer oleh Juergen Puls et al (2010) yang mempelajari efek lingkungan tanah terhadap biodegradasi selulosa menyatakan bahwa pato akan menunjukkan hasil yang signifikan selama 2 bulan dalam tanah yang basah (lembab) dan akan hancur seluruhnya kerja sinergis antara kegiatan beberapa mikroba (jamur dan bakteri) yang terlibat dalam proses biodegradasi (Abubakar, 2009). Data penurunan berat hasil penanaman plastik biodegradabel dapat dilihat pada Tabel 3. 
dihasilkan. Terjadinya perubahan gugus fungsi yang dialami limbah LDPE menandakan bahwa terjadinya interaksi kimia antara limbah LDPE dengan maleat anhidrida dan pati TKS. Analisis dengan spektrum infra merah ini dilakukan dengan cara mengamati frekuensi vibrasi yang khas dari gugus fungsi spektra FT-IR masing-masing sampel. Hasil spektra FT-IR yang dihasilkan dapat dilihat pada gambar 2 .

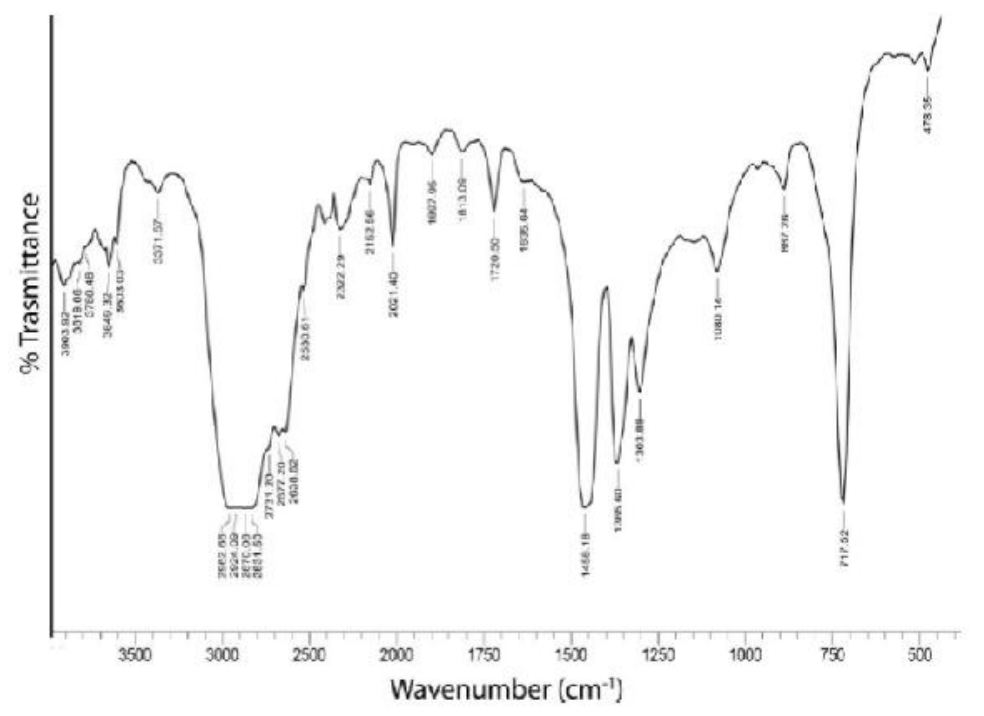

Gambar 2. Hasil Uji FT-IR dari Limbah LDPE

Analisis spektrum FT-IRlimbah LDPE pada bilangan gelombang $2962,66 \mathrm{~cm}^{-1}$ merupakan vibrasi ulur dari gugus - $\mathrm{CH}$ alkana (-CH: 3300$2900 \mathrm{~cm}^{-1}$ ). Pada bilangan gelombang lainya yaitu pada puncak $1458,18 \mathrm{~cm}^{-1}$ yang merupakan daerah ulur $-\mathrm{CH}(\mathrm{CH}$ lentur: $1300-1475 \mathrm{~cm}^{-1}$ ) dan pada panjang gelombang 2831,50 $\mathrm{cm}^{-1}$ merupakan serapan gugus etilen ($\left.\mathrm{CH}_{2}: \quad 3000-2700 \mathrm{~cm}^{-1}\right)$, sedangkan pada panjang gelombang $717-729 \mathrm{~cm}^{-}$ ${ }^{1}$ merupakan puncak serapan ikatan $\mathrm{CH}_{2}-\mathrm{CH}_{2}-\mathrm{CH}_{2}$-yang merupakan ciri khas spektrum LDPE. Berdasarkan adanya puncak-puncak untuk gugus $\mathrm{CH}_{2}$, - $\mathrm{CH}$, dan $\mathrm{CH}_{2^{-}} \mathrm{CH}_{2^{-}} \mathrm{CH}_{2^{-}}$ menandakan bahwa spektra ini adalah spektra dari limbah LDPE (Inggaweni, 2015).

Perubahan gugus fungsi dari spektra FT-IR Limbah LDPE, dapat dibandingkan dengan spektra dari plastik biodegradabel yang dihasilkan dengan perbandingan Limbah LDPE, Pati TKS, maleat anhidrida, benzoil peroksida (60:40:1:1) 


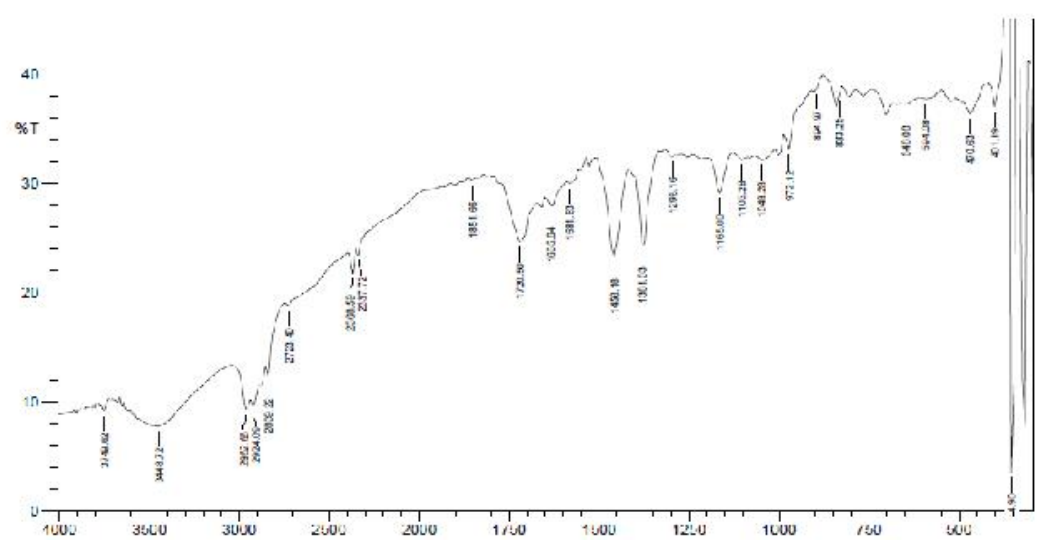

Gambar 3. Hasil Uji FT-IR Plastik Biodegradabel dengan perbandingan (60:40:1:1)

Dapat dilihat pada bilangan gelombang yang menunjukan gugus fungsi yang khas pada plastik biodegradabel yaitu bilangan gelombang $1165,00 \quad \mathrm{~cm}^{-1} \quad$ yang menunjukan gugus fungsi $\mathrm{C}-\mathrm{O}$ bending yang khas untuk menunjukan ikatan antara Limbah LDPE-g-MA dan pati yang didukung dengan bilangan gelombang $1627,92 \quad \mathrm{~cm}^{-1} \quad$ yang menunjukan gugus fungsi $\mathrm{C}=\mathrm{C}$ pada maleat anhidrida dan Limbah LDPE yang terikat silang. Serta beberapa gugus yang khas seperti pada limbah LDPE, dan bilangan gelombang 3433,29 yang menunjukkan gugus fungsi $\mathrm{O}-\mathrm{H}$ stretching yang khas untuk menunjukkan pati (Ruiz, 2011).

\section{KESIMPULAN}

Dengan penambahan maleat anhidrida sebagai agen pengikat silang antara pati dengan limbah plastik polipropilena, dengan bantuan inisiator benzoil peroksida, maka plastik biodegradabel yang dihasilkan tidak hanya berinteraksi secara fisika, namun juga berinteraksi secara kimia. Dari beberapa komposisi variasi massa maleat anhidrida dan benzoil peroksida yang ditambahkan, didapatkan kondisi oprimum plastik biodegradabel yang dihasilkan pada perbandingan limbah polipropilena, pati dari biji durian, maleat anhidrida, benzoil peroksida (94:6:1:1). Hal tersebut dapat disimpulkan berdasarkan hasil beberapa uji yang telah dilakukan yaitu uji sifat mekanik dengan uji tarik dimana diperoleh hasil harga kekuatan tarik $9,81 \mathrm{n} / \mathrm{m}^{2}$ dan kemuluran $0,5625 \%$. Hasil analisa sifat biodegradabelnya didapatkan penurunan massa yang telah ditanam selama 1 bulan yaitu pada tanah sampah sebesar 9,08\%. Interaksi kimia dari plastik biodegradabel yang dihasilkan dapat dilihat berdasarkan hasil analisa dengan ftir ditemukan bilangan gelombang $1165,00 \mathrm{~cm}^{-1}$ yang menunjukan gugus fungsi c-o bending yang khas untuk menunjukan ikatan antara limbah plastik polipropilena yang digrafting dengan maleat anhidrida dengan bantuan inisiator benzoil peroksida dan pati biji durian yang didukung dengan bilangan gelombang $1635,64 \mathrm{~cm}^{-1}$ yang menunjukan gugus fungsi $\mathrm{c}=\mathrm{c}$ pada maleat anhidrida dan polipropilena yang terikat silang dan bilangan gelombang 3448,72 yang menunjukkan gugus fungsi o-h stretching yang khas untuk menunjukkan pati.

\section{DAFTAR PUSTAKA}

Abubakar, 2009. Biodegradasi Bahan Komposit Polipropilena Dengan Pengisi Serat Limbah Padat ( Fibre 


\section{Eksakta Vol. 18 No. 2 Oktober | 2017}

E-ISSN : 2549-7464, P-ISSN : 1411-3724

Recovery ) Dari Pabrik Pulp dan Kertas. Tesis: FMIPA USU.

Ghaemy,Mousa.Roohina,Solaiman.2012.

Grafting of Maleic Anhydride on

Polyethylene in a Homogeneous

Medium in the Presence of Radical

Initiators. Iranian Polymer Journal, 12(1) (21-29)

Inggaweni,Luy.2015. Karakterisasi Sifat

Mekanik Plastik Biodegradable

Dari Komposit High Density

Polyethylene (Hdpe) Dan Pati Kulit

Singkong. Prosiding Seminar

Nasional Kimia, ISBN: 978-602-

0951-05-8. Jurusan Kimia FMIPA

Universitas Negeri Surabaya, 3-4

Oktober 2015

Pelita,Elda. Nirmala,Dyah.

Hidayani,Rachmi.2015. Pengaruh

Penambahan Maleat Anhidrida dan

Benzoil Peroksida Sebagai Agen

Pengikat Silang Pada Plastik

Biodegradabel dari Limbah

Polipropilena dengan Bahan Pengisi
Pati Biji Durian.Laporan Hasil

Penelitian. Politeknik ATI Padang

Ruiz,H.V.2011. Biodegradability of

Polyethylene-Starch Blens Prepared

by Extrusion and Molded by Injection: Evaluated by Respons Surface Methodology. Wiley-VCH Verlag GmbH 7 Co.KGaA, Weinheim. 63 (42-51)

Rutkowska,M.2002. Biodegradability of Polyethylene Starch Blends in Sea Water. Polish Journal of Enviromental Studies Vol. 11, No.3 (267-274)

Susilawati.2011.Biodegradable Plastics From A mixture of LDPE and Cassava Starch With Addition of Acrylic Acid. Jurnal Natural. Vol.11 No.2 (69-73)

Siswanto.2007.Pembuatan Plastik Polipropilena Pati Tapioca dengan Pemberian Maleat Anhidrida pada Saat Blending, Erlangga : Surabaya 